\title{
Spatial Estimation of the Impact of Airport Noise on Residential Housing Prices
}

\author{
Marco SAlvi ${ }^{\mathrm{a}}$
}

JEL-Classification: Q53, Q51, R31, L93, C21

Keywords: noise, airports, housing prices, hedonic pricing, spatial econometrics

\section{Introduction}

The impact of airport proximity on neighboring communities is a hotly debated topic. The positive aspects of proximity are related to the provision of communication links and to the direct economic importance of large airports. The downside of proximity are the adverse environmental effects primarily associated with aircraft noise. The growing interdependence and global connectivity of modern economies is bound to increase the economic importance of air travel. On the other hand, environmental quality tends to be a superior good - as per capita income rises, the social demand for environmental quality increases more than proportionally. It is fair to say that airport noise is likely to fuel ongoing public debate.

The recent story of Zurich Airport is in this regard exemplary. Until the year 2000 the use of German airspace for approaching and leaving Zurich airport had been governed by a bilateral agreement between Switzerland and Germany. The agreement was terminated by Germany in 2000, forcing the Swiss authorities to set out new landing procedures. As a result, the number of residents subject to aircraft noise increased significantly. Under the Swiss noise protection law these residents may be entitled to compensation and over 19000 have filed a claim. This has drastically increased the public awareness for the evaluation of the cost of noise. Specifically, the use of the hedonic method for the scope of evaluation and compensation has been proposed. Recently, the Federal Supreme Court of

a Ecole Polytechnique Fédérale, Lausanne, and Zürcher Kantonalbank, Zürich. Email: marco. salvi@epfl.ch. I am grateful to Patrik Schellenbauer, Philippe Thalmann, Adrian Lüscher, Gion-Reto Hassler, Alice Hollenstein and the editors for their helpful comments and suggestions. I thank the ZKB GIS-team for invaluable help with the GIS. The views expressed herein are my own and do not necessarily represent the views of the ZKB. 
Switzerland has decided that a version of the model presented in this paper will be used in the noise compensation litigations at Zurich Airport (SchweIzerisches BundESGERICHT, 2008). ${ }^{1}$

As with other nuisances, like air pollution or the proximity to landfill sites, the hedonic framework has been applied to measure the capitalization of airport noise in house prices. ${ }^{2}$ Although the market for quietness is missing, a complementary market exists wherein individuals reveal their willingness-to-pay to avoid different levels of aircraft noise exposure. In the recent empirical economic literature on noise valuation, surveyed in NELSON (2008), the question of the value placed by consumers on tranquillity has been typically estimated by regressing the house price (or rent) on selected structural and location characteristics.

Such hedonic regressions correspond only to the first of the two-step methodology proposed by Rosen's seminal paper (Rosen, 1974). As shown by EkeLand, Heckman and Nesheim (2002) the implicit price of noise does not readily identify the marginal valuation of consumers for quietness, bar restrictive conditions. The correct way to identify the willingness-to-pay for the characteristics of a differentiated good is an open subject of research and the present paper does not attempt identification. ${ }^{3}$ Still, the measurement of the implicit price for noise is of the foremost interest whenever - as with the case at hand - the compensation of neighbors is an issue.

This paper aims to establish the following contributions to the hedonic noise valuation literature:

1. Spatial statistics: Until recently, hedonic regressions were simply estimated by ordinary least squares (OLS). Thanks to advances in spatial econometrics and in statistical software, there is a rising awareness of the potential importance of spatial effects in hedonic modelling. ${ }^{4}$ However, most contributions have not

1 Many conditions have to be met in order to receive compensation. Residents must suffer a severe depreciation of the property, meaning a noise impact of at least $10 \%$ of the value. Only buyers of houses in areas where the noise increase was "not foreseeable" at the time of the transaction are entitled to compensation. The total sum of the compensations is estimated at around 1 billion Swiss francs.

2 See Palmquist (2004) for an overview of the use of hedonic valuation models. For other approaches to the valuation of airport noise, as contingent valuation or valuation based on happiness surveys, see NAVRUd (2002) and PraAG (2005), respectively.

3 For contributions, see Bajari and Benkard (2005); Bayer, McMillan and Ruben (2002), among others.

4 In their survey of the impact of landscape amenities on property prices, WALTERT and SCHLÄPFER (2007) identify seven studies which controlled for spatial autocorrelation, all of them published between 2000 and 2005 . 
considered spatial specifications issues, limiting themselves to a correction of spatial autocorrelation. ${ }^{5}$ Following the recommendations in Florax, Folmer and REY (2003), this paper carefully tests and accounts for the presence of spatial externalities. It then compares the results of different spatial specifications and evaluates the added-value of spatial statistics.

2. Disaggregate noise exposure data: Even for apparently similar locations near the runways, the noise intensity can vary greatly. Many factors influence the noise perceived at a given location, as, e.g., the sound diffraction of the terrain, the availability of instrument approach procedures or the weather. This paper uses a proprietary aircraft noise model provided by the Swiss Federal Laboratories for Materials Testing and Research (EMPA). The EMPA model was specifically calibrated and validated for use at Zurich airport. While many contributions have explicitly used aircraft noise data (as opposed to cruder measures of distance to the runways or flight paths), few have taken into account truly disaggregate noise data. Even the relatively recent contributions of McMiLLEN (2004) and the aforementioned study by CoHen and Coughuin (2006) has only access to a dummy variable indicating whether the transactions were located inside a given noise contour. Moreover, disaggregate data allow to distinguish between the impact of exposure over different periods of the day.

3. GIS coverage: This paper uses an extensive geodatabase. In addition to several accessibility variables, the database covers additional nuisances as road traffic noise. When measuring the impact of aircraft noise on property prices it is important to have access to good control variables as location variables are often highly correlated. A special effort is devoted here to the modelling of terrain characteristics, for example the presence of a scenic view. As a by-product, it is also possible to assess the added value of using precise geographical information.

4. Housing transactions: For around 4000 arm's-length transactions, actual selling prices were gathered, along with detailed structural characteristics. For each transaction an unusual high number of quality attributes were collected.

The organization of the remainder of this paper is the following. After a motivation of the use of spatial econometric techniques, Section 2 gives a short overview of the spatial model most likely to suit the case at hand. Section 3 gives a description of the sample of single-family housing transactions used in this paper, along with an account of the noise data. In Section 4 a range of explorative spatial

5 An exception is CoHen and Coughuin (2006), who explicitly consider the specification and estimation of a spatial model. 
data analysis is performed. Accordingly, a spatial setup is chosen. The results of both spatial and non-spatial estimation are presented and discussed in Section 5. Finally, conclusions are drawn in Section 6.

\section{Spatial Modelling}

\subsection{Why Use Spatial Econometrics?}

Spatial econometrics provides the researcher with a wide array of models and estimation techniques dealing with various kinds of spatial dependence. The correct representation of spatial externalities justifies - and indeed often requires - the specification and estimation of spatial econometric models (ANSELIN, 2003). Its use in real estate economics is growing and has been surveyed by Dubin, PACE and Thibodeau (1999). In spatial econometrics, dependencies that may arise through the interaction between neighboring locations are dealt with techniques similar to, but distinct from, those used in standard econometrics when dealing with issues of time dependence, heteroskedasticity or simultaneity.

In the case of the estimation of an hedonic regression in a real estate context, it is conceivable that houses heavily exposed to aircraft noise will be located in less affluent neighborhoods with lower building standards. If the covariates controlling for building quality and location in the hedonic regression are incomplete, some of the negative impact attributed to aircraft noise is in fact spurious and should be related to the lower quality of the building or location, not to the noise exposure. In general, a "correct" specification of the hedonic regression may require the gathering of a large amount of data, some of it - e.g. architectural style, or the presence of local amenities - may not usually be available to the researcher. This misspecification could entice a correlation between the estimation errors of neighboring observations subject to the influence of the same unobserved location characteristics. This kind of spatial dependence is known as spatial autocorrelation in the spatial econometrics literature. Ignoring this dependence is akin to the neglect of the time ordering of temporal series. As in this latter case, the OLS estimator is not efficient and the covariance matrix of the estimated parameters is not valid, even asymptotically. 


\subsection{How to Model Spatial Externalities}

Consider first the linear regression representing a simple hedonic model:

$$
y_{i}=x_{i}^{\prime} \beta+\varepsilon_{i}, i=1, \ldots, N
$$

where $y_{i}$ is the price of the $i$-th observation (corresponding to a housing unit $i$ ), $x_{i}$ is a $K$ by 1 vector of housing characteristics associated with the $K$ by 1 parameter vector $\beta$, and $\varepsilon_{i}$ is an element of a sequence of random error variables with $E\left[\varepsilon_{i}\right]=0$ and $N$ by $N$ variance-covariance matrix $\Omega_{\varepsilon}=E\left[\varepsilon \varepsilon^{\prime}\right]$. A spatial ordering specifies which element of $\Omega_{\varepsilon}$ is non-zero depending on the relative location $|i-j|$. To this purpose a $N$ by $N$ spatial weighting matrix $W$ is introduced which relates the realization of the random variable $\varepsilon_{i}$ to the values at neighboring locations. The matrix $W$ has elements $w_{i, j} \neq 0$ for the neighbors and $w_{i, j}=0$ otherwise. ${ }^{6}$ The most commonly used spatial process specification is the autoregressive model (SAR). It is given as

$$
\varepsilon_{i}=\lambda \sum_{j \neq i} w_{i j} \varepsilon_{j}+u_{i}
$$

where $\lambda$ is the spatial autoregressive parameter, $u_{i}$ is an element of a sequence of i.i.d. random error variables with $u_{i} \sim\left(0, \sigma_{u}^{2}\right)$. For this spatial process the corresponding variance-covariance matrix is

$$
\Omega_{\varepsilon}=\sigma_{u}^{2}\left[(I-\lambda W)^{-1}(I-\lambda W)^{\prime-1}\right] .
$$

As shown in ANSELIN (2003), with this specification every location is correlated with every other location, but closer locations more so. It is thus an example of "global" autocorrelation. A frequently used, alternative spatial specification is the spatial moving average (SMA), where (2) is replaced by

$$
\varepsilon_{i}=u_{i}-\rho \sum_{j \neq i} w_{i j} u_{j} .
$$

Here the error term $\varepsilon_{i}$ is only affected by directly interacting locations as given by the non-zero elements of $W$. The variance-covariance matrix of the SMA is

6 Diagonal elements $w_{i i}$ are set by convention to 0 . Typically, the spatial weight matrix is rowstandardized such that $\sum_{j=1}^{N} w_{i j}=1, \mathrm{i}=1, \ldots, N$. Although several alternative weighting schemes are possible, with row-standardized matrices weighting operations can be interpreted as an average of the neighboring values. 


$$
\Omega_{\varepsilon}=\sigma_{u}^{2}\left[I+\rho\left(W+W^{\prime}\right)+\rho^{2} W W^{\prime}\right] .
$$

Suppose the weighting matrix $W$ is defined as a first order contiguity matrix, where $w_{i j}=1$ whenever the observations $i, j$ are contiguous (according to some metric), or else $w_{i j}=0$. Two observations $l, m$ are second-order neighbors, if there exists some observation $r$ with $w_{l r}=1, w_{r m}=1$ and $w_{l m}=0$. The typical off-diagonal element of $\Omega_{\varepsilon}$ is non-zero only whenever the corresponding elements in $W\left(\right.$ or $\left.W^{\prime}\right)$ and $W W^{\prime}$ are non-zero. Such elements consist only of first and second-order neighbors. Higher-order neighbors are absent from $\Omega_{\varepsilon}$, and it is in this sense that the SMA model can be considered as representing "local" spatial dependence.

Spatial dependence could also be channelled through the regressors $W X$ or through a lagged dependent variable $W y$. For example, practitioners in the property market argue that due to the lack of transparency and liquidity of the residential real estate market, sellers and buyers often have to rely on transaction prices of "comparables" as their only source of price information. This may entice a spatial correlation between surrounding housing prices which would not be accounted for by the characteristics of the houses. It is thus tempting to add the spatially weighted average of the surrounding prices $W y$ to the model, i.e.

$$
y=\rho W y+X \beta+\varepsilon,
$$

where $\rho$ is the spatial autoregressive parameter. This so-called "spatial lag model" can be rewritten as

$$
y=(I-\rho W)^{-1} X \beta+(I-\rho W)^{-1} \varepsilon .
$$

In this case the dependent variable at a given location $y_{i}$ is partly determined by the error terms at all locations (ANSELIN, 2003). This generates an endogeneity which requires special estimation techniques, such as spatial versions of the Generalized Method of Moments (Kelejian and Prucha, 1999).

\subsection{Spatial Specification Searches}

In the absence of guidance by theory, the choice of spatial model is largely an empirical question. Recently, Florax, Folmer and Rey (2003) favored an approach based on a battery of specification tests performed on the OLS residuals of a hedonic regression. The tests are locally robust variations of the classical Lagrange Multiplier test. The first, denoted $L M_{\lambda}^{*}$, tests for the presence of 
a spatial autoregressive error (SAR) process, when the specification contains a spatially lagged dependent variable. It reads as

$$
L M_{\lambda}^{*}=\frac{\left(\hat{\varepsilon}^{\prime} W \hat{\varepsilon} / \hat{\sigma}^{2}-T(N J)^{-1} \hat{\varepsilon}^{\prime} W y \hat{\sigma}^{2}\right)^{2}}{T[1-T(N J)]^{-1}}
$$

with

$$
J=\frac{1}{N \hat{\sigma}^{2}}\left[(W X \hat{\beta})^{\prime} M(W X \hat{\beta})+T \hat{\sigma}^{2}\right]
$$

where $\hat{\varepsilon}$ is the vector of OLS residuals, $T$ is the trace of the matrix $\left(W^{\prime}+W\right) W$ and $M=I-X^{\prime}\left(X^{\prime} X\right)^{-1} X^{\prime}$. Under the null of no spatial autocorrelation, this statistic is $\chi^{2}(1)$-distributed. Alternatively, the test for a spatially lagged dependent variable in the presence of a spatial AR process, denoted $L M_{\rho}^{*}$ is defined as

$$
L M_{\rho}^{*}=\frac{\left(\hat{\varepsilon}^{\prime} W y-\hat{\varepsilon}^{\prime} W \hat{\varepsilon} / \hat{\sigma}^{2}\right)^{2}}{N J-T} .
$$

Under the null of no spatial dependence, this statistic is $\chi^{2}(1)$-distributed. Their testing strategy - dubbed "hybrid approach" - can be summarized as follows:

1. Estimate the hedonic regression (1) with OLS.

2. Test the hypothesis of no spatial dependence due to an omitted spatial lag or to spatially autoregressive errors, using $L M_{\rho}^{*}$ and $L M_{\lambda}^{*}$, respectively.

3. If both tests are not significant, the initial estimates from step 1 are used as the final specification. Otherwise proceed to step 4.

4. If only one test is significant, estimate the model accordingly. If both tests are significant, estimate the specification pointed to by the more significant of the two robust tests.

So, if $L M_{\lambda}^{*}$ is less significant than $L M_{\rho}^{*}$, a specification with a spatial AR process and without lagged dependent variable should be fitted. In the Monte-Carlo simulation reported in Florax, Folmer and Rey (2003), this hybrid approach fares well when compared to more complex alternative modelling strategies. It is also adopted in the present paper. 


\section{Data}

\subsection{EMPA Aircraft Noise Data}

Zurich Airport is Switzerland's largest airport with about 260000 take-offs and landings per year. The Swiss Federal Laboratories for Materials Testing and Research (EMPA) have provided model-based aircraft noise data in the vicinity of Zurich airport area on a regular basis. As with other aircraft noise models, the EMPA model produces noise exposure contours based on terrain, effective radar flight track information and aircraft noise profile. In addition, further variables influencing the local acoustic environment are explicitly modelled, as, for example, the effect of the prevalent winds. ${ }^{7}$ The EMPA data set used in this paper consists of average noise immissions measured according to different variants of the $L_{e q}$ (noise equivalence level) metric. The measures are available over varying time intervals, the hourly interval being the shortest. The noise contours are laid on a $100 \mathrm{~m}$-by- $100 \mathrm{~m}$ square lattice grid. Each pixel represents the average noise immission affecting a given location during a specific time interval over the course of one year. For each location and for each year dating back to 1987, a set of 24 hourly average noise levels is available. The aircraft data corresponding to the sale year is matched to each housing transaction. ${ }^{8}$

The $L_{e q}$ metric maps noise events into an equivalent continuous, A-weighted sound pressure level, measured in decibel $(\mathrm{dB})$. A-weighting adjusts sound pressure towards the frequency range of human hearing. The $L_{e q}$ metric corresponds to the steady sound level that, over a specified period of time would produce the same energy equivalence as the fluctuating sound level actually occurring.

$L_{e q}$ is routinely used in the measurement of noise exposure, although its justification as a single-number descriptor of aircraft noise is subject to considerable debate (JonEs, 1997). The debate pertains in particular to the time span over which the aggregation should be performed. Averaging over many hours smoothes out peaks in the noise exposure. At Zurich Airport runaway patterns vary considerably over the course of the day. Some locations are affected only during the evening hours, others only in the morning. For these locations, averaging over daytime may result in low overall $L_{e q}$ values, although the residents are exposed

7 See Thomann, Bütikofer and Krebs (2004) for a detailed description of the EMPA aircraft noise model.

8 Only noise exposures over $50 \mathrm{~dB}(\mathrm{~A})$ are considered here. Exposures under this cut-off are too low to be reliably estimated by the EMPA model (G. Thomann, pers. comm.). We put these observations on the same level as the lack of noise. 
to significant noise during peak hours. Home-owners may perceive the location as noisy, irrespective of the low average noise measures. To further investigate this issue we consider three distinct noise metrics:

- $L_{e q}$ 16h: The equivalent continuous noise level measured over 16 daytime hours, starting at $6 \mathrm{am}$ and ending at $10 \mathrm{pm}$. This metric measures the "mean" noise level at a given location. It is considered in the Swiss noise abatement legislation.

- $L_{e q}$ peak: The highest 1-hour $L_{e q}$ measured during daytime (i.e. from 6 am to $10 \mathrm{pm}$ ), in excess of $L_{e q} 16 \mathrm{~h}$. This measure is meant to capture the peak-level, daytime noise which might be "averaged out" by the $L_{e q}$ measure.

- $L_{\text {eq }}$ evening: The average noise level measured between $9 \mathrm{pm}$ and $11 \mathrm{pm}$. This metric captures noise exposure during the sensitive evening hours, when most residents are at home and try to get to sleep.

The three metrics shall represent different "shades" of aircraft noise. Due to the changing runway patterns and flying paths the metrics are largely uncorrelated.' Figure 1 traces out the noise contours with exposure over $50 \mathrm{~dB}$ for the three different metrics. Notice that we do not consider night-time and early morning exposure. Zurich airport has the strictest night flying rules in the whole of Europe. The night-time flying ban essentially provides that there are to be no flights between the hours of midnight and $6 \mathrm{am}$. As for early morning noise, significant exposure in the South-East started in late 2003. At the time of writing, not enough property transactions were available in this region to allow for the separate modelling of the morning noise effects. This is left for future work.

\subsection{Residential Housing Sales Data}

A second data set of single-family home transactions in the Canton of Zurich was provided by a regional mortgage originator. It contains 3947 observations occurred between 1995 and 2005.759 transactions are subject to various degrees of aircraft noise, i.e. they are within the $50 \mathrm{~dB}$ noise contour levels depicted in Figure 1. The rest is not subject to airport noise as previously defined and is scattered around the Canton of Zurich. In addition to the transaction prices,

9 The correlation coefficient between mean and peak noise exposure levels is $\rho=0.05$. Mean exposure and evening exposure are not correlated $(\rho=0.04)$, while the evening and the peak metrics are slightly negatively correlated $(\rho=-0.14)$, reflecting runways alternation. 
the records contain detailed descriptions of key features of each house, such as lot size, volume, number of rooms, age, an assessment of the state of the building and several other structural characteristics listed in Table 1, along with their respective descriptive statistics.

Figure 1. Zurich Airport Noise Contour Levels in 2005.

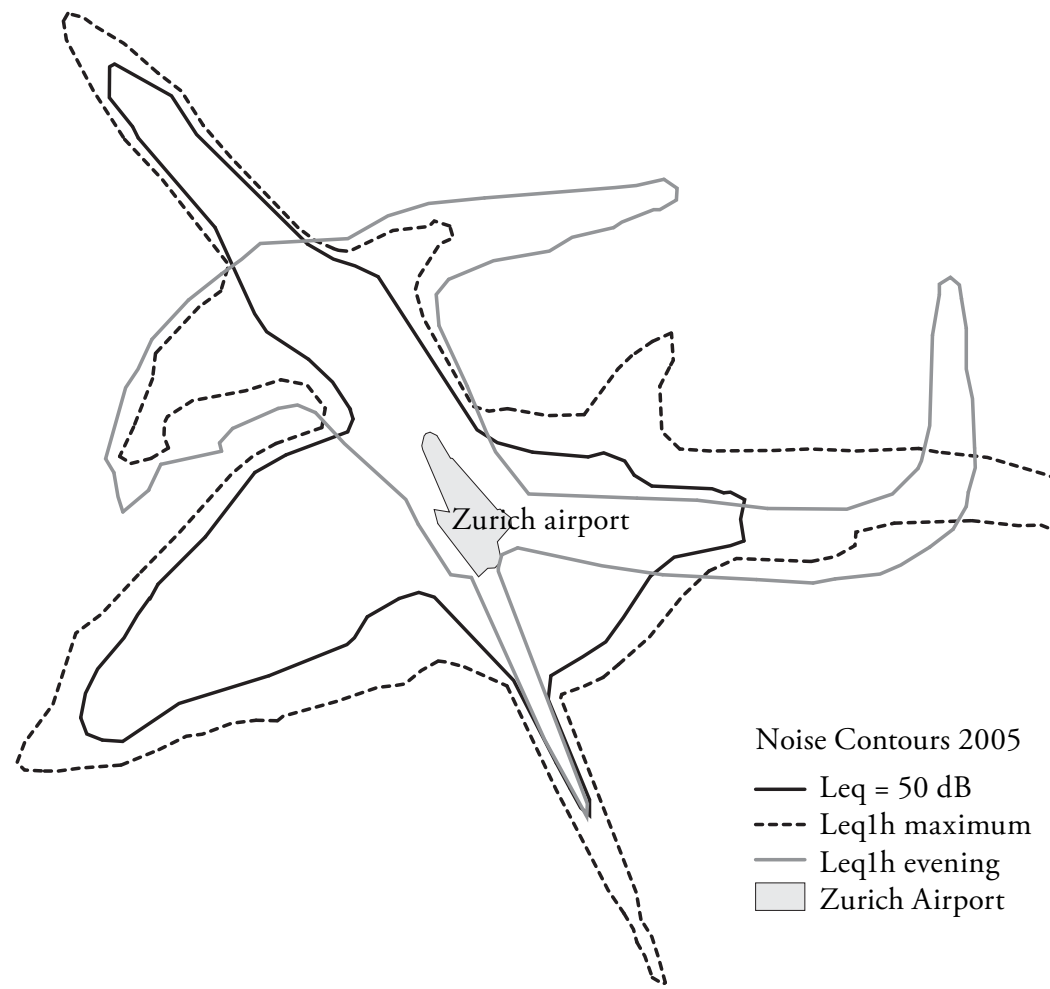

The figure shows the $50 \mathrm{~dB}$ noise contour for the three different metrics used in the model. Although the contours are largely overlapping, for observations in excess of the $50 \mathrm{~dB} L_{e q} 16 \mathrm{~h}$ threshold, the three metrics are only weakly correlated. The correlation coefficients are $\rho=0.05$ between $L_{e q} 16 \mathrm{~h}$ and the $L_{e q}$ peak metric, and $\rho=0.038$ between $L_{e q} 16 \mathrm{~h}$ and the evening noise metric. The latter metric is weakly negatively correlated with the peak measures $(\rho=-0.14)$, primarily reflecting runways alternations during the day. 
Table 1: Descriptive Statistics of the House Characteristics

\begin{tabular}{|c|c|c|c|c|c|}
\hline Variable & Mean & Median & Min & Max & Std. Dev \\
\hline House price [CHF 1000] & 772.16 & 727.00 & 155.00 & 2600.00 & 262.94 \\
\hline \multicolumn{6}{|l|}{ Continuous variables) } \\
\hline Lot size $\left[\mathrm{m}^{2}\right]$ & 521.62 & 447.00 & 150.00 & 2430.00 & 315.61 \\
\hline Size, volume of building $\left[\mathrm{m}^{3}\right]$ & 723.12 & 691.00 & 350.00 & 1995.00 & 220.67 \\
\hline Number of rooms & 5.49 & 5.00 & 2.00 & 11.00 & 1.15 \\
\hline Number of bathrooms & 2.27 & 2.00 & 1.00 & 6.00 & 0.73 \\
\hline Age of building [years] & 30.76 & 21.00 & 0.00 & 156.00 & 32.67 \\
\hline \multicolumn{6}{|l|}{ Categorical variables } \\
\hline \multicolumn{6}{|l|}{ Condition of the dwelling } \\
\hline New & 0.36 & & & & \\
\hline Renovated & 0.13 & & & & \\
\hline Well maintained & 0.41 & & & & \\
\hline Needs renovation & 0.10 & & & & \\
\hline Brick building & 0.95 & & & & \\
\hline Detached & 0.46 & & & & \\
\hline Cellar & 0.95 & & & & \\
\hline Double glazing & 0.66 & & & & \\
\hline Floor heating & 0.45 & & & & \\
\hline Garage & 0.49 & & & & \\
\hline Underground garage & 0.25 & & & & \\
\hline Modern kitchen & 0.33 & & & & \\
\hline Swimming pool & 0.02 & & & & \\
\hline Sauna & 0.04 & & & & \\
\hline
\end{tabular}

The table reports the descriptive statistics of the 3737 observations included in the final sample. The original data set contained 3967 transactions single-family homes sold at arm's length in the Canton of Zurich between 1995 and 2005. 230 observations (5.8\%) were excluded because of likely data entry mistakes, of which 178 transactions with very small lot sizes under $150 \mathrm{~m}^{2}$. We suspect that for these transactions, the house living area was erroneously entered. 
Table 2: Descriptive Statistics of the Location Characteristics

\begin{tabular}{lrrrrr}
\hline Variable & Mean & Median & Min & Max & Std. Dev \\
\hline Aircraft noise (in excess of 50 dB) & & & & & \\
\hline $\mathrm{L}_{\text {eq }}$ 16h [dB] & 1.11 & 0.00 & 0.00 & 20.40 & 2.84 \\
$\mathrm{~L}_{\text {eq }}$ Evening [dB] & 0.24 & 0.00 & 0.00 & 16.10 & 1.25 \\
$\mathrm{~L}_{\text {eq }}$ 1h Peak [dB] & 0.67 & 0.00 & 0.00 & 8.20 & 1.50 \\
Location variables & & & & & \\
Road traffic noise, Lr 16h [dB] & 0.78 & 0.00 & 0.00 & 18.50 & 2.55 \\
View on lakes [ha] & 512.00 & 0.00 & 0.00 & 6971.00 & 1236.00 \\
View on Alps [km ${ }^{2}$ ] & 187.83 & 168.83 & 0.00 & 986.48 & 132.56 \\
Travel distance to CBD [min] & 32.9 & 33.00 & 12.00 & 56.00 & 8.01 \\
Near power line (<200m) & 0.03 & 0.00 & 0.00 & 1.00 & 0.16 \\
Near railway (<100m) & 0.09 & 0.00 & 0.00 & 1.00 & 0.28 \\
Slope terrain [\%] & 4.59 & 3.83 & 0.13 & 21.33 & 3.49 \\
Aspect: East & 0.28 & 0.00 & 0.00 & 1.00 & 0.45 \\
Aspect: West & 0.44 & 0.00 & 0.00 & 1.00 & 0.50 \\
Share of Swiss residents & 0.84 & 1.00 & 0.00 & 1.00 & 0.36 \\
Maximum built density [\%] & 43.48 & 40.00 & 15.00 & 333.00 & 18.89 \\
Community tax revenue [Index] & 106.78 & 90.93 & 42.34 & 511.42 & 51.95 \\
\hline
\end{tabular}

The location variables were matched at the hectare level with each of the 3737 single-family homes, sold in the Canton of Zurich between 1995 and 2005. The aircraft noise exposure and, where possible, the other location variables are those of the transaction year. All noise variables are reported as the values in excess of $50 \mathrm{~dB}(\mathrm{~A})$. Daytime car travel noise is measured with the $\mathrm{Lr}$ metric (rating level). The distance to CBD is measured as the car travel time to Zurich Main station. Aspect (orientation) dummies are computed only for terrains with a slope greater than $1 \%$. The share of Swiss residents is computed in a neighborhood of $300 \mathrm{~m}$ around the transaction. View variables are computed at 4 meters above ground. The density variables report the maximum allowed built density on the lot expressed as the ratio of the living space to the lot size. The community tax is the communal per capita tax revenue. See the main text for further explanations. 
The transaction data were matched to the aircraft noise data and with several further geographic features and attributes of the location, listed and described in Table 2. The geographic attributes include measures of accessibility (travel distance to the Central Business District (CBD) by car and by public transportation), environmental amenities (exposition, view, steepness of the terrain), neighborhood characteristics (building density, socioeconomic composition) and measures of additional nuisances (road traffic and train noise). Note that, as with the aircraft noise, a $50 \mathrm{~dB}$ threshold was used for the road traffic noise variable. With the help of a digital terrain model the extent of the view on two major amenities - the lakes and the Swiss Alps - were simulated for each of the 54000 built hectares in the Canton of Zurich and matched to the property database.

\section{Empirical Results}

\subsection{Explorative Spatial Analysis of the Residential Housing Sales Data}

In spatial econometrics, the choice of the weighting scheme is crucial as it captures the pattern of interaction of neighboring units. Ideally, this choice ought to be guided by theory, but in many applied settings, existing theory is compatible with several possible weighting schemes.

The setting considered here suggests a weighting scheme based on the Euclidean distance between houses (with possibly a cap at a given distance), or on a contiguity metric. As a consequence of land-use regulation, vacant adjacent land lots tend to be developed roughly at the same time. Houses built on these lots are likely to be similar, reflecting the supply and demand conditions prevalent at the time of development (e.g. similar construction technology, demographic patterns or architectural tastes). On the other hand, both noise measurements and house locations are available to us only up to a precision of \pm 100 meters, which limits the use of the Euclidean distance metric and favors an approach based on contiguity, as the nearest-neighbor metric. Two exploratory techniques can guide us in the specification of the spatial model. The first - the estimation of the empirical variogram - is of help when choosing an adequate weighting scheme. The second involves the formal testing for spatial correlation.

\subsubsection{Variogram Estimates}

The empirical variogram estimates the degree of spatial dependence between two locations. We compute estimates for both the raw log housing prices and for the residuals of the hedonic regression of log prices on the housing characteristics and 
Figure 2. Sample Variograms for the Raw Log Prices (a) and OLS Residuals (b).
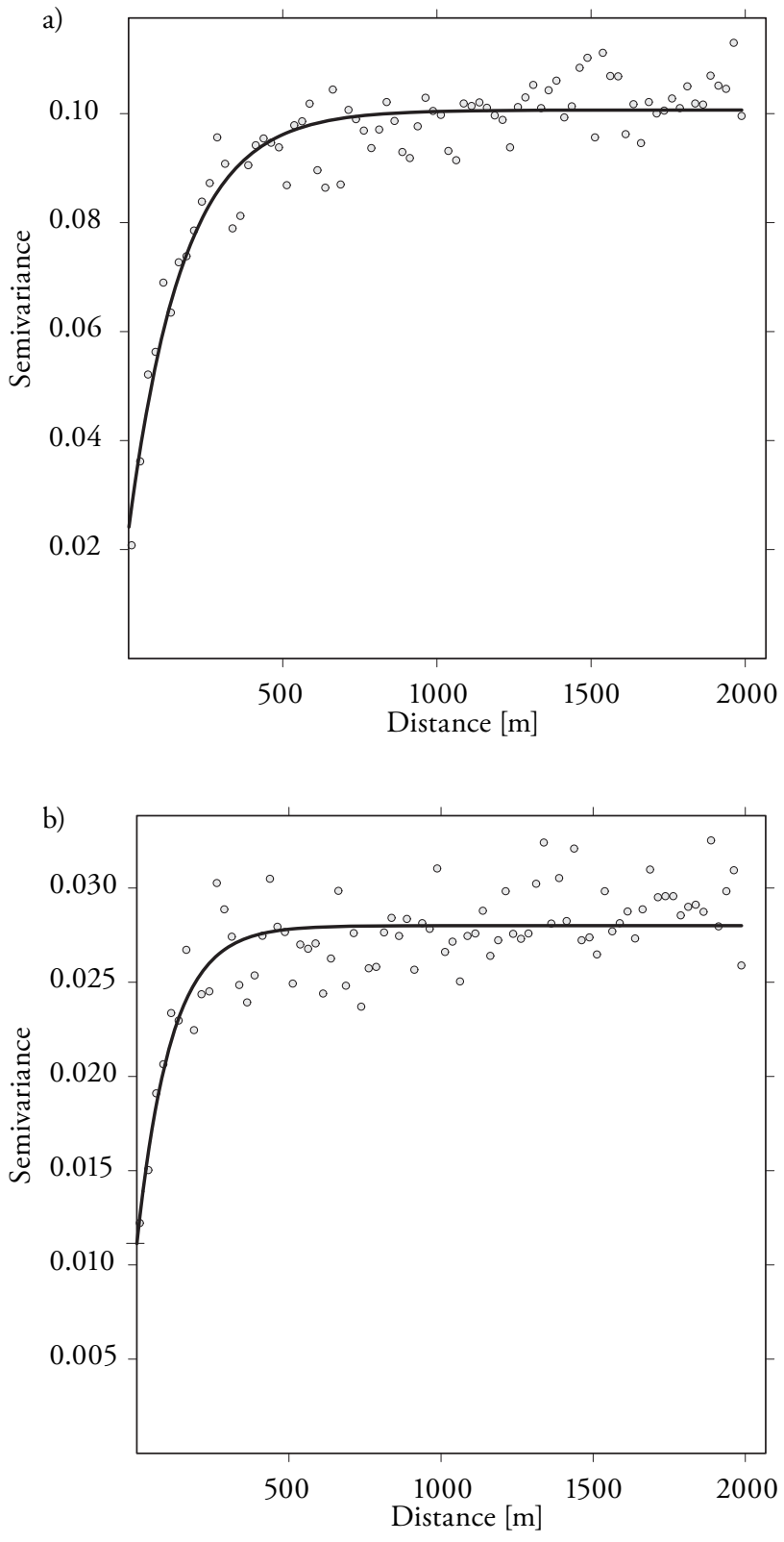
on the attributes of the location. The results of the empirical variogram estimation are presented in Figure 2. We use a robust estimator of $\gamma(h)$ - the semivariogram at distance $h$ - suggested by CRESSIE (1993).

The sample semivariogram $\gamma(h)$ at different distances shows a positive correlation at short lags of both the raw data (the log selling prices) and the OLS residuals. Correlation of the OLS residuals decreases rapidly with increasing distance, and the sill is reached at a distance of about 300 meters, lending some weight to the choice of a scheme based on contiguity and distance up to this range. In the following we perform spatial analysis using three different spatial matrices; two of them based on the Euclidean distance, the third on nearest-neighbor contiguity. For the distance-based spatial weight matrix $W$, define $w_{i j}=1$ for $d_{i j} \leq c$, and $w_{i j}=0$ otherwise, $d_{i j}$ being the estimated Euclidean distance between $i$ and $j$, and $c$ is the cut-off value. Upon consideration of the semivariogram, the cutoff values for the distance based matrices were set at $c_{1}=300 \mathrm{~m}$ and $c_{2}=600 \mathrm{~m}$, respectively. Both matrices are subsequently row-standardized so that the row's elements sum to one. In the third matrix the neighbor structure is constrained to the four nearest-neighbors. More than $70 \%$ of the observations have at least four neighbors within a radius of 300 meters.

\subsubsection{Testing for Spatial Dependency and Spatial Autocorrelation}

Formal testing for spatial correlation is performed with two different tests and three different spatial weight matrices. We report two variants of Moran's I classical test for spatial correlation, first proposed by Cliff and Ord (1972). The first relies on asymptotic normality while the other does not. ${ }^{10}$ Moran's $I$ statistic for the residuals of a linear regression $\hat{\varepsilon}$ is defined as

$$
I=\frac{N \sum_{i=1}^{N} \sum_{j \neq i}^{N} w_{i j} \hat{\varepsilon}_{i} \hat{\varepsilon}_{j}}{\sum_{i=1}^{N} \sum_{j \neq i}^{N} w_{i j} \sum_{i=1}^{N} \hat{\varepsilon}_{j}^{2}} .
$$

The expected value of $I$ is $E[I]=-1 / N$ and its variance is

$$
\operatorname{Var}[I]=\frac{N\left[\left(N^{2}-3 N+3\right) S_{1}-N S_{2}+3 S_{0}^{2}\right]-b_{2} J}{(N-1)(N-2)(N-3) S_{0}^{2}}-E^{2}(I)
$$

10 The tests and the estimation methods used in the rest of the paper are implemented in the R package spdep. 
where

$$
\begin{gathered}
J=\left[\left(N^{2}-N\right) S_{1}-2 N S_{2}+6 S_{0}^{2}\right], S_{0}=\sum_{i=1}^{N} \sum_{j}^{N}\left(w_{i j}+w_{j i} / 2\right), \\
S_{1}=\sum_{i=1}^{N} \sum_{j=1}^{N}\left(w_{i j}+w_{j i}\right)^{2} / 2, \quad S_{2}=\sum_{i=1}^{N}\left(w_{i .}+w_{. i}\right)^{2} \\
\text { with } w_{i .}=\sum_{j=1}^{N} w_{i j} \text { and } b_{2}=N \sum_{i=1}^{N} \hat{\varepsilon}_{i}^{4} /\left(\sum_{i=1}^{N} \hat{\varepsilon}_{i}^{2}\right)^{2} .
\end{gathered}
$$

Under general regularity conditions on the weighting matrix $W$ the standardized $I$ statistic $I^{*}=(I-E[I]) / \sqrt{\operatorname{Var}[I]}$ is asymptotically distributed as a standard normal. The alternative inference results are based on the 500 random permutations of the residual map. Computation of Moran's I statistic for the permutations provides the rank of the observed statistic and gives a consistent estimate of the $p$-value. In Table 3 we report the spatial correlation tests of the log house prices and the corresponding results for the OLS residuals.

Table 3: Spatial Correlation Tests

\begin{tabular}{lcccc}
\hline Spatial weight matrix & Moran's $I$ & $p$-value & MC simulation & $p$-value \\
\hline Log house prices & & & & \\
Euclidean, cut-off $600 \mathrm{~m}$ & 0.3250 & $<0.001$ & 0.3512 & $<0.001$ \\
Euclidean, cut-off $300 \mathrm{~m}$ & 0.3025 & $<0.001$ & 0.3064 & $<0.001$ \\
Nearest-neighbor $(\mathrm{NN}=4)$ & 0.3422 & $<0.001$ & 0.3528 & $<0.001$ \\
OLS residuals & & & & \\
Euclidean, cut-off $600 \mathrm{~m}$ & 0.1441 & $<0.001$ & 0.1557 & $<0.001$ \\
Euclidean, cut-off $300 \mathrm{~m}$ & 0.1368 & $<0.001$ & 0.1363 & $<0.001$ \\
Nearest-neighbor $(\mathrm{NN}=4)$ & 0.1457 & $<0.001$ & 0.1534 & $<0.001$ \\
\hline
\end{tabular}

The spatial correlation tests are computed for both the raw data and the residuals of the OLS estimation of the basic hedonic model. The statistics are reported for three different specifications of the spatial weight matrix. The first two spatial matrices are based on an Euclidean norm, with cut-off points at 300 and 600 meters, respectively. The third is a contiguity matrix where we consider the four nearest neighbors.

Both the normal approximation and the bootstrap tests very clearly reject the null of the absence of spatial correlation in the house price data and in the OLS residuals. The $I$ statistics are similar across all three different spatial weighting 
matrices under consideration. We conclude that - from the point of view of statistical inference - the explorative analysis and the correlation tests strongly points to the need of incorporating the spatial structure of the data into the empirical analysis.

\subsubsection{Spatial Specification Tests}

This subsection is devoted to the choice of the spatial model specification. We here follow the approach sketched in Section 2 in choosing between the two spatial models considered in the literature: the spatial lag model and the linear model with spatial autocorrelation. The results are reported in Table 4.

Table 4: Spatial Specification Tests

\begin{tabular}{lrrrr}
\hline Spatial weight matrix & $L M_{\rho}^{*}$ & $p$-value & $L M_{\lambda}^{*}$ & $p$-value \\
\hline Euclidean, cut-off $600 \mathrm{~m}$ & 1.88 & 0.180 & 136.11 & $<0.001$ \\
Euclidean, cut-off $300 \mathrm{~m}$ & 15.46 & $<0.001$ & 249.34 & $<0.001$ \\
Nearest-neighbor $(\mathrm{NN}=4)$ & 8.45 & 0.004 & 210.48 & $<0.002$ \\
\hline
\end{tabular}

The spatial specification tests are performed with three different specifications of the spatial weight matrix. Lagrange Multiplier statistics are reported with their marginal significance levels.

The first entry in the table $\left(L M_{\rho}^{*}\right)$ summarizes the results of the test for endogenous spatial lag dependence (see equation (10)). The alternative statistic, denoted $L M_{\lambda}^{*}$, tests for the presence of a spatial AR error process. For the three spatial matrices under consideration, both tests reject their respective null hypothesis, with one exception. The absence of spatial dependency cannot be rejected at the shortest range $(300 \mathrm{~m})$. Notice that the rejection is much stronger for the autocorrelation test, as apparent from the higher Lagrange Multiplier statistic. In this case, Florax, Folmer and Rey (2003) argue for the specification of a model without lagged endogenous variable and with a spatial autoregressive error structure. We follow here their advice.

\subsection{Estimation of the Spatial Model}

On the strength of the analysis in the previous section a spatial model is fit to the GIS-augmented single family home data set. The error follows a SAR process as in equation (2). We report the results of Maximum Likelihood estimation 
of the spatial model in Table 5 (Model 1 and 2) for different specifications of the aircraft noise, alongside the results of the OLS estimation of a non-spatial specification (Model 3).

Table 5: Estimation Results: SAR Models and Non-Spatial Hedonic Regression

\begin{tabular}{lcc|cc|cc}
\hline & \multicolumn{2}{c|}{ Model 1 (ML SAR) } & \multicolumn{2}{|c|}{ Model 2 (ML SAR) } & \multicolumn{2}{|c}{ Model 3 (OLS) } \\
Variable & Estimate & SE & Estimate & SE & Estimate & SE \\
\hline Intercept & 9.2801 & 0.1337 & 9.3899 & 0.1083 & 9.2325 & 0.1253 \\
\hline $\mathrm{L}_{\text {eq }}$ 16h & -0.0098 & 0.0010 & -0.0070 & 0.0013 & -0.0098 & 0.0009 \\
$\mathrm{~L}_{\text {eq }}$ Evening & & & -0.0064 & 0.0019 & & \\
$\mathrm{~L}_{\text {eq }}$ 1h Peak & & & -0.0063 & 0.0023 & & \\
Age of building & -0.0028 & 0.000 & -0.0029 & 0.0003 & -0.0026 & 0.0003 \\
\hline Age squared & 0.0007 & 0.000 & 0.0007 & 0.0002 & 0.0006 & 0.0002 \\
\hline New & 0.1377 & 0.012 & 0.1373 & 0.0116 & 0.1358 & 0.0119 \\
Renovated & 0.1451 & 0.009 & 0.1452 & 0.0093 & 0.1419 & 0.0096 \\
Well maintained & 0.1126 & 0.008 & 0.1125 & 0.0080 & 0.1096 & 0.0082 \\
Brick building & 0.0284 & 0.009 & 0.0290 & 0.0092 & 0.0298 & 0.0094 \\
Detached & 0.0256 & 0.006 & 0.0264 & 0.0056 & 0.0253 & 0.0057 \\
\hline Cellar & 0.0476 & 0.010 & 0.0478 & 0.0103 & 0.0487 & 0.0106 \\
\hline Double glazing & 0.0312 & 0.005 & 0.0317 & 0.0055 & 0.0322 & 0.0056 \\
\hline Floor heating & 0.0356 & 0.006 & 0.0359 & 0.0064 & 0.0357 & 0.0066 \\
Garage & 0.0253 & 0.005 & 0.0257 & 0.0055 & 0.0253 & 0.0056 \\
\hline Underground garage & 0.0290 & 0.007 & 0.0293 & 0.0071 & 0.0264 & 0.0072 \\
\hline Modern kitchen & 0.0589 & 0.005 & 0.0586 & 0.0052 & 0.0592 & 0.0054 \\
\hline Swimming pool & 0.0637 & 0.015 & 0.0641 & 0.0147 & 0.0653 & 0.0152 \\
Sauna & 0.0396 & 0.011 & 0.0396 & 0.0109 & 0.0379 & 0.0113 \\
\hline
\end{tabular}

11 ML estimation requires the repeated evaluation of the information matrix, which is computationally demanding in this context (PACE and GILley, 1998). Therefore, we use a sparse matrix implementation. 


\begin{tabular}{|c|c|c|c|c|c|c|}
\hline \multirow[b]{2}{*}{ Variable } & \multicolumn{2}{|c|}{ Model 1 (ML SAR) } & \multicolumn{2}{|c|}{ Model 2 (ML SAR) } & \multicolumn{2}{|c|}{ Model 3 (OLS) } \\
\hline & Estimate & SE & Estimate & SE & Estimate & SE \\
\hline Log lot size & 0.1691 & 0.006 & 0.1692 & 0.0059 & 0.1646 & 0.0060 \\
\hline Log size & 0.4163 & 0.011 & 0.4155 & 0.0111 & 0.4206 & 0.0113 \\
\hline Log rooms & 0.1243 & 0.013 & 0.1246 & 0.0130 & 0.1223 & 0.0134 \\
\hline Log bathrooms & 0.1005 & 0.008 & 0.0998 & 0.0078 & 0.1018 & 0.0080 \\
\hline Share Swiss residents & 0.0149 & 0.006 & 0.0157 & 0.0064 & 0.0159 & 0.0063 \\
\hline Road traffic noise & -0.0050 & 0.001 & -0.0051 & 0.0009 & -0.0053 & 0.0009 \\
\hline Log travel dist. to CBD & -0.2310 & 0.015 & -0.2354 & 0.0151 & -0.2290 & 0.0133 \\
\hline Low density $(<40 \%)$ & -0.0034 & 0.006 & -0.0040 & 0.0059 & -0.0044 & 0.0056 \\
\hline Middle density (40-50\%) & -0.0024 & 0.007 & -0.0029 & 0.0068 & -0.0034 & 0.0065 \\
\hline Higher density (> 50\%) & -0.0117 & 0.007 & -0.0126 & 0.0072 & -0.0132 & 0.0070 \\
\hline Lake view $>0-20 \mathrm{~km}^{2}$ & 0.0552 & 0.007 & 0.0514 & 0.0066 & 0.0563 & 0.0059 \\
\hline Lake view $20-40 \mathrm{~km}^{2}$ & 0.1390 & 0.012 & 0.1346 & 0.0118 & 0.1411 & 0.0107 \\
\hline Lake view $>40 \mathrm{~km}^{2}$ & 0.1121 & 0.014 & 0.1074 & 0.0138 & 0.1103 & 0.0120 \\
\hline View $50-100 \mathrm{~km}^{2}$ & 0.0359 & 0.009 & 0.0357 & 0.0091 & 0.0406 & 0.0084 \\
\hline View $100-250 \mathrm{~km}^{2}$ & 0.0236 & 0.008 & 0.0244 & 0.0078 & 0.0270 & 0.0071 \\
\hline View $>250 \mathrm{~km}^{2}$ & 0.0163 & 0.009 & 0.0183 & 0.0090 & 0.0159 & 0.0081 \\
\hline Slope 0-9\% & 0.0194 & 0.006 & 0.0191 & 0.0061 & 0.0191 & 0.0060 \\
\hline Slope $>9 \%$ & 0.0357 & 0.008 & 0.0360 & 0.0080 & 0.0353 & 0.0076 \\
\hline Near power line & -0.0103 & 0.015 & -0.0133 & 0.0150 & -0.0118 & 0.0140 \\
\hline Near railway & -0.0243 & 0.008 & -0.0237 & 0.0082 & -0.0247 & 0.0078 \\
\hline Aspect: East & -0.0032 & 0.007 & -0.0034 & 0.0068 & -0.0002 & 0.0064 \\
\hline Aspect: West & 0.0102 & 0.006 & 0.0093 & 0.0063 & 0.0139 & 0.0060 \\
\hline Log tax revenue & 0.1559 & 0.010 & 0.1568 & 0.0099 & 0.1549 & 0.0089 \\
\hline$\rho$ & 0.1852 & & 0.1853 & & - & \\
\hline LR test ( $p$-value) & $<0.001$ & & $<0.001$ & & - & \\
\hline Residual standard error & 0.1279 & & 0.1275 & & 0.1309 & \\
\hline $\mathrm{N}$ & 3737 & & 3737 & & 3737 & \\
\hline Log likelihood & 2364 & & 2374 & & & \\
\hline AIC & -4625 & & -4640 & & & \\
\hline
\end{tabular}

For reasons of space, yearly time dummies are not reported here. They are available from the author upon request. 
All estimated regressions show a satisfactory overall goodness-of-fit, as illustrated by the low standard errors of estimation ( $12.8 \%$ for Model 1). Structural and location attributes of the houses are strongly significant and have the expected sign, the principal characteristics driving house prices being the volume (size) of the building, its age, lot size and the centrality of location. ${ }^{12}$ The elasticity of sale prices with respect to the travel time to the Zurich $\mathrm{CBD}$ is -0.231 , meaning that a one minute increase from 10 to 11 minutes will cut the sale price of a CHF 1 million home by approximatively CHF 20600 . Properties with a extended view over a lake command a high premium, up to $15 \%$, other things being equal. This premium is much higher than the one paid for an extended view on the mountains, possibly reflecting the relative abundance of such views in Switzerland. ${ }^{13}$

\subsubsection{Noise Discounts}

Aircraft noise exposures may enter the hedonic regression with several specifications. In the first specification (Model 1), only the mean daytime noise exposure enters the hedonic regression. This is the basic specification considered in the meta-analysis of Schipper, Nijkamp and Rietveld (1998) and Nelson (2004). In this case,the corresponding Noise Depreciation Index (NDI) is $0.97 \%$, i.e. a noise increase of $1 \mathrm{~dB}$ corresponds to a $0.97 \%$ lower house prices. Noise is highly significant. The standard deviation of the NDI is low at $0.12 \%$. The $95 \%$ confidence interval $(0.68 \%-1.17 \%)$ encompasses the average NDI of $0.83 \%$ reported by Schipper, Nijkamp and Rietveld (1998). ${ }^{14}$ However, our NDI estimate is substantially higher than the average cumulative noise discount of $0.5 \%$ to $0.6 \%$ reported by NeLson (2004). It is close to the NDI of $0.7 \%$ found by BaranzinI and RAMirez (2005)in a recent study based on rental apartments located in the vicinity of Geneva airport.

In addition to the results of the base model, Table 5 also reports results for the full noise exposure specification (Model 2). Again, the hedonic regression

12 For reasons of space, both the time and the community dummies are not reported. They are available from the author upon request.

13 Notice that view is defined as the maximum number of hectares visible from a given location (obstacles as trees or other buildings are not accounted for in this simulation). This is a very crude metric to judge the attractiveness of a view. In particular, it is independent of the distance of the point of interest.

14 Schipper, Nijkamp and Rietveld (1998) also report a regression of the NDI on housing wealth, measured as the mean house price divided by per capita income. For our sample we would expect a higher than average NDI of $-1.2 \%$, reflecting the comparatively high housing wealth in the region of Zurich. 
measures this impact quite precisely, as signalled by the small standard errors, which are adjusted for spatial autocorrelation. All the noise exposure measures, i.e. the mean and peak noise exposure (as captured by the $L_{e q} 16 \mathrm{~h}$ and $L_{e q} \max$ ) and evening noise are statistically highly significant. An increase in mean daytime noise exposure of $1 \mathrm{~dB}$ is associated with a decrease in prices of $0.70 \%$. An independent $1 \mathrm{~dB}$ increase in evening noise exposure impacts prices with $-0.64 \%$. A similar increase in peak noise knocks off $0.63 \%$ from the prices.

Although aircraft noise has an evident impact on house prices, the overall noise discounts are of relatively moderate magnitude. Based on either the base of the fully specified model estimates, typical discounts are in the $-2 \%$ to $-8 \%$ range.

Only $10 \%$ of the discounts are in excess of $-10 \%$. This, however, also reflects the fact that single-family homes tend to be built on prime (i.e. less noisy) locations. Areas heavily affected by aircraft noise tend to attract other types of developments like offices and logistic property. Finally, we notice that in the base specification, the NDI for road traffic is $-0.53 \%$ (standard error $0.11 \%$ ). Adding an extra $\mathrm{dB}$ of motor vehicle noise affects property prices slightly less than aircraft noise.

\subsubsection{Spatial Estimation}

Although the tests clearly reject the absence of spatial correlation, the difference between the OLS and the spatial regression results is minimal. This is visible in Table 5 where we compare the previous results of Model 1 and Model 2 with those of an OLS regression (Model 3). Inference based on the OLS residuals is virtually unchanged, despite the fact that the standard errors are not corrected for spatial correlation. The reason for the modest contribution of spatiality is evident when we consider the magnitude of the spatial autoregressive parameter $\rho$, reported at the bottom of the table. The point estimate is $\rho=0.1852$, indicating only a weak positive correlation between errors of adjacent locations. Indeed, from equation (3) recall that the variance-covariance matrix for the random vector $\varepsilon$ is proportional to the product of the inverse matrix $(I-\rho W)^{-1}$ with its transpose. This matrix can be expanded as follows

$$
(I-\rho W)^{-1}=I+\rho W+\rho^{2} W^{2}+\ldots
$$

With weights $\rho=0.185, \rho^{2}=0.034$, the higher terms in the expansion quickly decay. In other words, the spatial autocorrelation component - although statistically highly significant - is small from an economical point of view. Accordingly, its impact on inference results is negligible. 
In spatial econometric applications, the choice of spatial matrix may cause greater differences in parameter estimates than the choice of estimation technique. This is unsatisfactory as this choice remains largely untested and many possible matrices are compatible with the underlying economic story. We thus conclude the spatial econometric section by reporting the results of the estimation of Model 1 given alternative choices for the spatial matrices. The results are reported in Table 6, in the columns labelled Model 4 (for the weighting matrix with cut-off at $600 \mathrm{~m}$ ) and Model 5 (for the weighting matrix based on nearestneighbor contiguity).

Table 6: ML SAR Estimation Results with Alternative Weighting Schemes

\begin{tabular}{lcc|cc|cc}
\hline & \multicolumn{2}{c|}{ Model $4(\mathrm{c}=600 \mathrm{~m})$} & \multicolumn{2}{|c|}{ Model $5(\mathrm{NN})$} & \multicolumn{2}{|c}{ Model 6 (No GIS) } \\
Variable & Estimate & SE & Estimate & SE & Estimate & SE \\
\hline Intercept & 9.3800 & 0.1137 & 9.3701 & 0.1124 & 9.3226 & 0.0840 \\
\hline $\mathrm{L}_{\text {eq }}$ 16h & -0.0099 & 0.0011 & -0.0099 & 0.0010 & -0.0086 & 0.0023 \\
Age of building & -0.0030 & 0.0003 & -0.0030 & 0.0003 & -0.0034 & 0.0003 \\
\hline Age squared & 0.0008 & 0.0002 & 0.0008 & 0.0002 & 0.0010 & 0.0002 \\
New & 0.1359 & 0.0116 & 0.1367 & 0.0116 & 0.1271 & 0.0117 \\
\hline Renovated & 0.1443 & 0.0093 & 0.1448 & 0.0092 & 0.1491 & 0.0093 \\
Well maintained & 0.1119 & 0.0080 & 0.1119 & 0.0080 & 0.1111 & 0.0080 \\
\hline Brick building & 0.0290 & 0.0093 & 0.0278 & 0.0093 & 0.0280 & 0.0093 \\
Detached & 0.0277 & 0.0056 & 0.0271 & 0.0056 & 0.0267 & 0.0057 \\
Cellar & 0.0468 & 0.0103 & 0.0458 & 0.0103 & 0.0441 & 0.0104 \\
Double glazing & 0.0340 & 0.0055 & 0.0326 & 0.0055 & 0.0291 & 0.0055 \\
\hline Floor heating & 0.0333 & 0.0064 & 0.0349 & 0.0064 & 0.0326 & 0.0065 \\
\hline Garage & 0.0254 & 0.0055 & 0.0259 & 0.0055 & 0.0278 & 0.0056 \\
\hline Underground garage & 0.0270 & 0.0071 & 0.0289 & 0.0072 & 0.0287 & 0.0073 \\
\hline Modern kitchen & 0.0587 & 0.0053 & 0.0585 & 0.0052 & 0.0634 & 0.0053 \\
\hline Swimming pool & 0.0598 & 0.0147 & 0.0624 & 0.0147 & 0.0587 & 0.0149 \\
\hline Sauna & 0.0391 & 0.0109 & 0.0378 & 0.0109 & 0.0526 & 0.0110 \\
\hline Log lot size & 0.1700 & 0.0059 & 0.1693 & 0.0060 & 0.1786 & 0.0059 \\
\hline Log size & 0.4165 & 0.0111 & 0.4158 & 0.0112 & 0.4223 & 0.0113 \\
\hline
\end{tabular}




\begin{tabular}{|c|c|c|c|c|c|c|}
\hline \multirow[b]{2}{*}{ Variable } & \multicolumn{2}{|c|}{ Model $4(\mathrm{c}=600 \mathrm{~m})$} & \multicolumn{2}{|c|}{ Model $5(\mathrm{NN})$} & \multicolumn{2}{|c|}{ Model 6 (No GIS) } \\
\hline & Estimate & SE & Estimate & SE & Estimate & SE \\
\hline Log rooms & 0.1199 & 0.0130 & 0.1207 & 0.0130 & 0.1246 & 0.0131 \\
\hline Log bathrooms & 0.0960 & 0.0077 & 0.0969 & 0.0077 & 0.0969 & 0.0078 \\
\hline Share Swiss residents & 0.0160 & 0.0064 & 0.0169 & 0.0066 & & \\
\hline Road traffic noise & -0.0053 & 0.0009 & -0.0054 & 0.0009 & & \\
\hline Log travel dist. to CBD & -0.2335 & 0.0162 & -0.2307 & 0.0159 & & \\
\hline Low density $(<40 \%)$ & -0.0077 & 0.0059 & -0.0045 & 0.0060 & & \\
\hline Middle density (40-50\%) & -0.0065 & 0.0068 & -0.0027 & 0.0069 & & \\
\hline Higher density (> 50\%) & -0.0145 & 0.0072 & -0.0120 & 0.0073 & & \\
\hline Lake view $>0-20 \mathrm{~km}^{2}$ & 0.0545 & 0.0067 & 0.0557 & 0.0067 & & \\
\hline Lake view $20-40 \mathrm{~km}^{2}$ & 0.1318 & 0.0123 & 0.1357 & 0.0122 & & \\
\hline Lake view $>40 \mathrm{~km}^{2}$ & 0.1080 & 0.0146 & 0.1119 & 0.0144 & & \\
\hline View $50-100 \mathrm{~km}^{2}$ & 0.0319 & 0.0092 & 0.0344 & 0.0093 & & \\
\hline View $100-250 \mathrm{~km}^{2}$ & 0.0213 & 0.0081 & 0.0216 & 0.0080 & & \\
\hline View $>250 \mathrm{~km}^{2}$ & 0.0135 & 0.0093 & 0.0137 & 0.0092 & & \\
\hline Slope $0-9 \%$ & 0.0171 & 0.0060 & 0.0177 & 0.0061 & & \\
\hline Slope $>9 \%$ & 0.0357 & 0.0080 & 0.0345 & 0.0081 & & \\
\hline Near power line & -0.0090 & 0.0151 & -0.0064 & 0.0154 & & \\
\hline Near railway & -0.0244 & 0.0080 & -0.0228 & 0.0083 & & \\
\hline Aspect: East & -0.0032 & 0.0068 & -0.0031 & 0.0069 & & \\
\hline Aspect: West & 0.0093 & 0.0063 & 0.0106 & 0.0065 & & \\
\hline Log tax revenue & 0.1588 & 0.0107 & 0.1599 & 0.0105 & & \\
\hline$\rho$ & 0.2579 & & 0.2233 & & 0.1453 & \\
\hline LR test ( $p$-value) & $<0.001$ & & $<0.001$ & & $<0.001$ & \\
\hline Residual standard error & 0.1276 & & 0.1274 & & 0.1263 & \\
\hline $\mathrm{N}$ & 3737 & & 3737 & & 3737 & \\
\hline AIC & -4640 & & -4645 & & -4439 & \\
\hline
\end{tabular}

Model 4 uses a contiguity matrix with a cut-off value set at $600 \mathrm{~m}$, while in Model 5 it is constrained to the four nearest neighbors. For Model 6 the same weighting matrix as in Model 1 of Table 5 is used, with GIS-matched location variables replaced by community indicator variables. For reasons of space, both the time and the community dummies are not reported. 
Both alternative weighting matrices are associated with marginally higher, positive spatial autocorrelation parameters $\rho$. Accordingly, the standard error of the estimated coefficients are somewhat higher. Nevertheless, as far as the added value of the spatial econometric specification is concerned, this analysis confirms the previous negative results.

\subsubsection{Robustness of Results}

Higher noise levels may exert a disproportionate impact on house prices - an effect not captured by a crude linear specification. In order to examine this issue we reformulate Model 1 as a generalized additive model. This nonparametric estimation method relaxes the assumption of log-linearity of the mean noise exposure, allowing for a more flexible functional form (Hastie and TiвSHIRANI, 1990). The nonparametric component is modelled as a third-order spline. Figure 3 illustrates the result of the estimation where we report the nonparametric fit with the respective $95 \%$-confidence interval.

Figure 3. Non-Parametric Estimation of the Impact of Mean Noise Exposure.

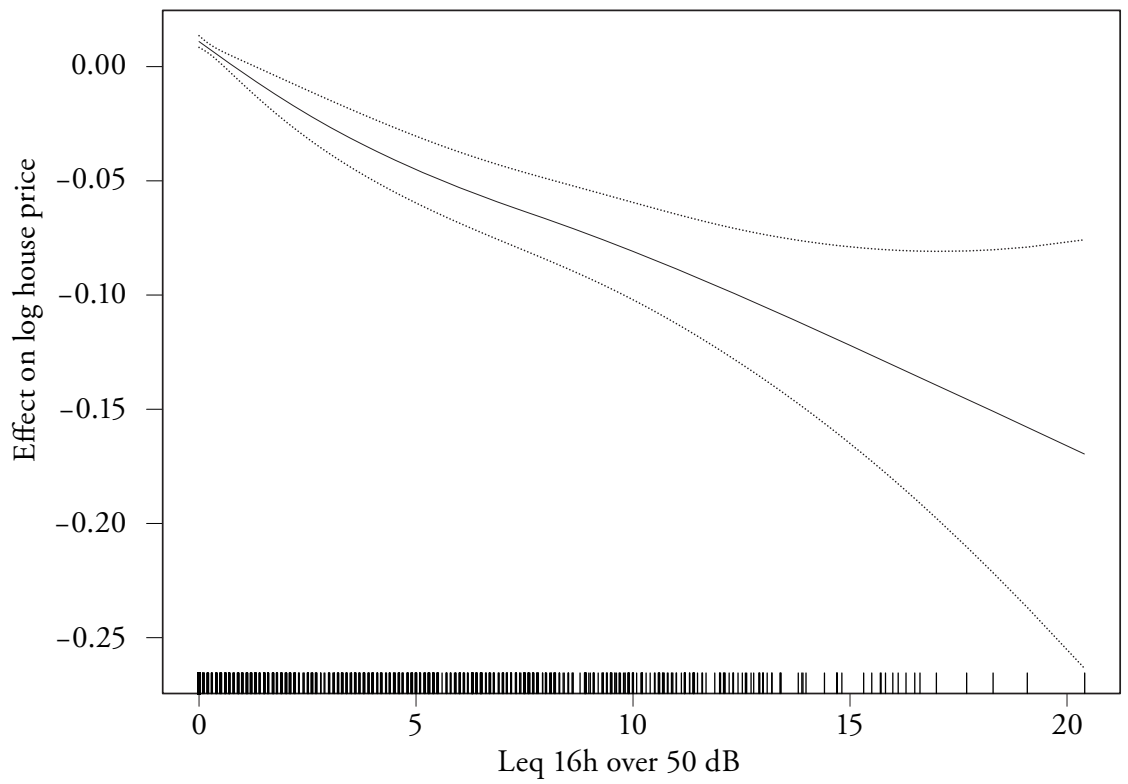

The nonparametric component is modelled as a third-order spline.

The dotted lines represent the $95 \%$ confidence interval. 
The visual inspection of the results shows that non-parametric specification is broadly supportive of the log-linear assumption. Nonetheless, the slightly $S$-shaped fitted spline points to a more than proportional effect at both the lower and the higher end of the noise distribution, i.e. for $L_{e q}$ levels between 52 and 55 $\mathrm{dB}$ and for exposures higher than $65 \mathrm{~dB}$, respectively. Interestingly, this confirms (at least informally) results in the acoustic literature which have also identified non-linearities at equivalent thresholds. ${ }^{15}$

As a further challenge to the stability of the result, we re-estimate Model 1 with an interaction effect between time and the mean noise exposure. The estimated interaction term is plotted in Figure 4.

Figure 4. Estimated Interaction Effect between Time of Transaction and NDI.

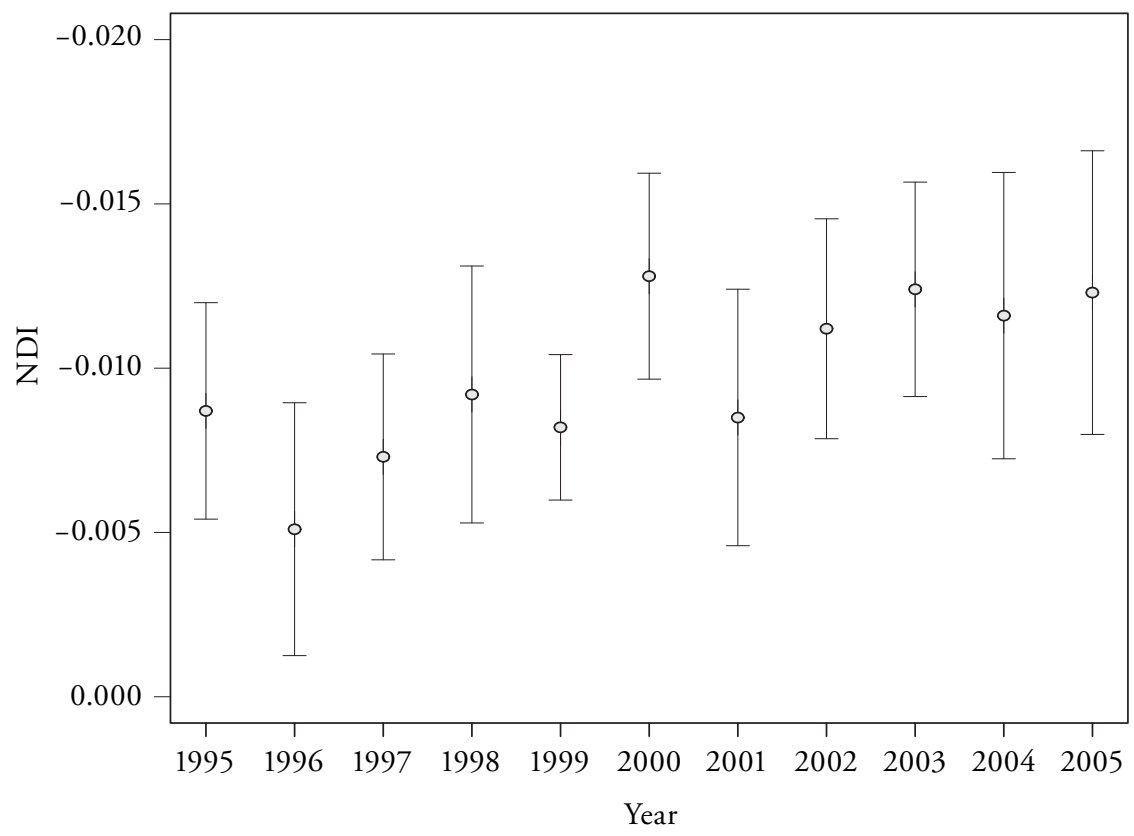

The error bars represent the $95 \%$ confidence interval. The base-case NDI $(0.97 \%)$ is within the $95 \%$ confidence interval of all time-specific NDI estimates.

15 For example, a similar response pattern is found in a study based on a questionnaire survey sent to residents in the vicinity of Zurich airport (WirTh, Brink and Scherz, 2006). 
A visual inspection of the results shows some increase in the NDI since the year 2000, which - incidentally - is the year when the bilateral agreement between Switzerland and Germany was terminated. However, our base-case NDI (0.97\%) is within the $95 \%$ confidence interval of all time-specific NDI estimates, which shows that the NDI is relatively stable over the years.

Finally, we turn the focus of the analysis to the contribution of the geographical variables to the precision of our estimates. Notwithstanding the growing availability of GIS-coverage, the gathering of a wide range of spatially referenced data remains costly. It thus makes sense to compare the explanatory power of the regression with the GIS-matched location variables to the much cheaper modelling alternative which only includes an indicator variable for each one of the 171 communities in the Canton of Zurich. In the latter case, indicator variables act as a catch-all for the location characteristics, which are assumed not to vary within a community. Still, aircraft noise variables are matched to a precise location. The results of this specification are presented in the last two columns of Table 6. Casual inspection of the results indicates that the implicit prices of the structural attributes (size, age, quality etc.) are very close to those obtained with the fuller specifications. The suppression of the location variables exerts a weak impact on the remaining geo-referenced variable, aircraft noise. Although the noise coefficient remains strongly statistically significant, the NDI drops somewhat to $-0.86 \%$. However, the general fit of the model does not worsen, as signalled by the higher log likelihood and the slightly higher standard error of regression. As the aircraft noise exposure is limited to specific communities adjacent to the airport, the inclusion of community fixed-effects captures a significant part of the noise variation. Richer specifications which include geo-referenced variables allow us to avoid this masking effect.

\section{Conclusions}

The purpose of this paper is to evaluate the impact of aircraft noise on the housing prices in the Zurich Airport area applying spatial econometric techniques. Based on a large and detailed sample of single-family homes transaction we estimate a NDI of slightly under $1 \%$ per extra $\mathrm{dB}$. This is a comparatively high estimate, at least when confronted with the results surveyed in Nelson (2004) which covers 33 studies for 23 airports in North America. A possible explanation for the high Swiss NDI estimates - other than pure sample variability - is the income effect evidenced in Schipper, Nijkamp and Rietveld (1998). The studies surveyed in Nelson (2004) stem for the great majority from the 1970s, 
the most recent study uses data from the early 1990s. During the last two decades, rising incomes may have increased demand, if, as it is likely, quietness is a superior good. Another possible explanation, this time related to the noise measurement, is given by the technological advances that have made newer airplanes significantly quieter. The number of noise events enters the $L_{e q}$ metric logarithmically, while the intensity of the event has a linear impact on it. If the perceived noise by the home-owners has stayed constant, the high estimates could be partly offsetting lower measured $L_{e q}$. Inspection of Figure 4 suggests a slightly higher NDI towards the end of the sample which coincides with generally lower mean exposure levels. ${ }^{16}$ We leave this question as a topic for further research.

As spatial correlation in the OLS residuals was detected, several estimation techniques suggested by the relatively new and emergent spatial econometric literature have been applied. The noise estimates are robust to different choices of spatial weighting matrix and to different methods of estimation. From an economic point of view, the added value of the spatial econometric technique is negligible. However, real estate research has to cope with the potential misspecification induced by the spatial nature of the data. From this point of view, spatial statistics does increase the level of confidence in the results. There are, however, alternative ways to measure the impact of noise which may be even less prone to misspecification biases. The sudden and unexpected change of runways at Zurich Airport has exposed some neighborhoods to aircraft noise which had been so far free from it. This natural experiment setting suggests the use of a difference-indifferences (DID) estimator. As already pointed out earlier, at the time of writing, not enough property transactions were available in this region to allow for a specific modelling. This is left for future work.

Of course, this analysis is not yet sufficient for a balanced evaluation of the welfare costs associated with aircraft noise, as it merely estimates the hedonic price of noise and does not attempt to identify the demand for quietness. Almost thirty years after the publication of Rosen's seminal paper, the issues regarding the full identification and estimation of hedonic models have only been recently clarified by the works of several researchers (Ekeland, Heckman and Nesheim, 2002; BAJARI and KAHN, 2002, among others). This gives another lead to further research.

16 In the first half of the sample (1995-2000) a quarter of the transactions in the airport perimeter were subject to a daytime $L_{e q}$ in excess of $8.2 \mathrm{~dB}$. In the second half of the sample the $25 \%$-percentile is $7.2 \mathrm{~dB}$. 


\section{References}

Anselin, Luc (2003), "Spatial Externalities, Spatial Multipliers, and Spatial Econometrics”, International Regional Science Review, 26 (2), pp. 153-166.

Bajari, Patrik, and C. Lanier Benkard (2005), "Demand Estimation with Heterogenous Consumers and Unobserved Product Characteristics: A Hedonic Approach", Journal of Political Economy, 113 (6), pp. 1239-1276.

Bajari, Patrik, and Mattew H. Kahn (2002), "Estimating Housing Demand with an Application to Explaining Racial Segregation in Cities", working paper.

Baranzini, Andrea, and José Ramirez (2005), "Paying for Quietness: The Impact of Noise on Geneva Rents", Urban Studies, 42 (4), pp. 633-646.

Bayer, Patrick, Robert McMillan and Kim Ruben (2002), "The Causes and Consequences of Residential Segregation: An Equilibrium Analysis of Neighborhood Sorting", working paper.

Cliff, Andy D., and John Keith Ord (1972), "Testing for Spatial Autocorrelation Among Regression Residuals”, Geographic Analysis, 4, pp. 267-284.

Cohen, Jefrrey P., and Cletus C. Coughuin (2006), "Spatial Hedonic Models of Airport Noise, Proximity, and Housing Prices", working paper.

Cressie, Noel A. (1993), Statistics for Spatial Data, New York.

Dubin, Robin A., R. Kelley Pace and Thomas G. Thibodeau (1999), "Spatial Autoregression Techniques for Real Estate Data", Journal of Real Estate Literature, 7 (1), pp.79-95.

Ekeland, Ivar, James J. Heckman and Lars Nesheim (2002), "Identification and Estimation of Hedonic Models", working paper.

Florax, Raymond J. G. M., Hendrik Folmer and Sergio J. Rey (2003), "Specification Searches in Spatial Econometrics: The Relevance of Hendry's Methodology", Regional Science and Urban Economics, 33 (5), pp. 557-579. Hastie, T., and R. Tibshirani (1990), General Additive Models, New York. Jones, H. F. (1997), Validity of Leq as a Predictor of the Impact of Aircraft Noise on People, Tech. rep., Heathrow Association for the Control of Aircraft Noise.

Kelejian, Harry H., and Ingmar R. Prucha (1999), "A Generalized Moments Estimator for the Autoregressive Parameter in a Spatial Model", International Economic Review, 40 (2).

McMillen, Daniel P. (2004), "Airport Expansions and Property Values", Journal of Urban Economic, 55 (3), pp. 627-640.

Navrud, StÅle (2002), The State-Of-The-Art on Economic Valuation of Noise. Final Report to EC/DG Environment, Tech. rep. 
Nelson, Jon P. (2004), "Meta-Analysis of Airport Noise and Hedonic Property Values: Problems and Prospects", Journal of Transport Economics and Policy, 38 (1), pp. 1-27.

Nelson, Jon P. (2008), "Hedonic Property Value Studies of Transportation Noise: Aircraft and Road Traffic", in Andrea Baranzini, José Ramirez, Caroline Schaerer and Philippe Thalmann (eds), Hedonic Model in Housing Markets, Berlin.

Pace, R. Kelley, and Otis W. Gilley (1998), "Generalizing the OLS and Grid Estimators", Real Estate Economics, 26, pp.331-347.

Palmquist, Raymond B. (2004), "Property Valuation Models", in Karl-Göran Mäler and Jefferey Vincent (eds), Handbook of Environmental Economics, Amsterdam.

Rosen, Sherwin (1974), "Hedonic Prices and Implicit Markets: Product Differentiation in Pure Competition", Journal of Political Economy, 82, pp.34-55.

Schipper, Youdi, Peter Nijkamp and Piet Rietveld (1998), "Why Do Aircraft Noise Estimates Differ? A Meta-Analysis", Journal of Air Transportation Management, 4, pp. 117-124.

SChweizerisches Bundesgericht (2008), „Enteignung nachbarrechtlicher Abwehrbefugnisse infolge Fluglärms sowie von Abwehrrechten gegen den direkten Überflug ausgehend vom Landesflughafen Zürich“, BGE $1 \mathrm{E} .15 / 2007$.

Thomann, Georg, Rudolf Bütikofer and Walter Krebs (2004), FLUla2: Ein Verfahren zur Berechnung und Darstellung der Fluglärmbelastung, Tech. rep., Swiss Federal Laboratories for Materials Testing and Research.

van Praag, Bernard M. S., and Barbara E. Baarsma (2005), "Using Happiness Surveys to Value Intangibles: The Case of Airport Noise", Economic Journal, 115 (500), pp. 224-246.

Waltert, Fabian, and Felix Schläpfer (2007), “The Role of Landscape Amenities in Regional Development: A Survey of Migration, Regional Economic and Hedonic Pricing Studies", working paper.

Wirth, Katja, Mark Brink and Christoph Schierz (2006), Lärmstudie 2000. Schlussbericht der 2. Befragungsstudie vom August 2003, Tech. rep., ETH Zürich, Zentrum für Organisations- und Arbeitswissenschaften. 


\section{SUMMARY}

The paper applies spatial econometric techniques to measure the impact of airport noise on the price of single-family homes in the Zurich Airport area. We exploit a large database of geo-referenced noise measurements to investigate the reaction of prices to different noise metrics. The particular institutional setting of Zurich Airport, with changing patterns of runways configurations allows to distinguish the impact of noise at different times of the day. The use of neighborhood fixedeffects is compared to the results given by a costlier modelling strategy involving a rich set of location descriptors. The paper documents the impact of airport noise on housing prices. In the base model specification the Noise Discount Index is $0.97 \%$ with typical discounts in the range of $-2 \%$ to $-8 \%$. Accounting for the spatiality of the data has little effect on the results. 